Please do not remove this page

RMIT

UNIVERSITY

\title{
Effect of disbonds on the fatigue endurance of composite scarf joints
}

Goh, Jun; Georgiadis, Steve; Orifici, Adrian; Wang, Chun

https://researchrepository.rmit.edu.au/esploro/outputs/9921859909801341/filesAndLinks?institution=61RMIT_INST\&index=null

Goh, J., Georgiadis, S., Orifici, A., \& Wang, C. (2014). Effect of disbonds on the fatigue endurance of composite scarf joints. Advanced Materials Research, 891-892, 191-196.

https://doi.org/10.4028/www.scientific.net/AMR.891-892.191

Document Version: Accepted Manuscript

Published Version: https://doi.org/10.4028/www.scientific.net/AMR.891-892.191

Repository homepage: https://researchrepository.rmit.edu.au

(C) (2014) Trans Tech Publications. Switzerland

Downloaded On 2023/04/26 22:41:34 +1000

Please do not remove this page 
Thank you for downloading this document from the RMIT Research Repository.

The RMIT Research Repository is an open access database showcasing the research outputs of RMIT University researchers.

RMIT Research Repository: http://researchbank.rmit.edu.au/

\section{Citation:}

Goh, J, Georgiadis, S, Orifici, A and Wang, C 2014, 'Effect of disbonds on the fatigue endurance of composite scarf joints', Advanced Materials Research, vol. 891892, pp. 191-196.

See this record in the RMIT Research Repository at:

https://researchbank.rmit.edu.au/view/rmit:27216

Version: Accepted Manuscript

Copyright Statement: (C) (2014) Trans Tech Publications. Switzerland

Link to Published Version:

http://dx.doi.org/10.4028/www.scientific.net/AMR.891-892.191 


\title{
Effect of Disbonds on the Fatigue Endurance of Composite Scarf Joints
}

\author{
J.Y.Goh ${ }^{1}$, S. Georgiadis ${ }^{2}$, A.C.Orifici ${ }^{1}$, C.H.Wang ${ }^{1 *}$ \\ ${ }^{1}$ School of Aerospace, Mechanical and Manufacturing Engineering, RMIT University, Melbourne, \\ Australia \\ ${ }^{2}$ Boeing Research \& Technology Australia, Melbourne, Australia \\ ${ }^{*}$ Corresponding author. Email: chun.wang@rmit.edu.au
}

Keywords: Fracture mechanics, composite, damage tolerance, finite element, scarf joint

\begin{abstract}
The certification of scarf repairs requires that the repair is capable of handling flight loads in the presence of disbonds. This paper presents a study of the fatigue disbond growth behaviour of scarf joints. By determining the strain energy release rates of a disbond in a scarf joint subjected to a unit load, a predictive model based on linear elastic fracture mechanics is presented, which is shown to correlate well with experimental results. This method offers a promising technique for predicting the fatigue life of composite scarf joints with disbonds.
\end{abstract}

\section{Introduction}

A key airworthiness certification requirement for adhesively bonded scarf repairs of aircraft composite structures is to demonstrate through analysis or tests that catastrophic failure due to fatigue, environmental effects, manufacturing defects, or accidental damage will be avoided throughout the operational life of the aircraft [1]. While methods for predicting the residual strength of composite structures, without repairs [2] and with repairs [3, 4], are available in literature, there is a lack of analytical methods that can predict the growth rates of disbonds in scarf repairs. While the fatigue properties of a composite material can be determined using double cantilever beam (DCB) and end notched flexure (ENF) tests, it is not clear how the fatigue endurance of scarf repairs can be estimated. This paper aims to present a fracture mechanics based approach for predicting the disbond growth rate and fatigue life of scarf joints containing pre-existing flaws.

\section{Theory}

The growth rate of disbonds in composite structures under fatigue loading is commonly expressed in terms of the cyclic strain energy release rate, $\Delta G=G_{\max }-G_{\min }$, where the parameters $C$ and $m$ depend on the material and the loading ratio (defined as the ratio between the minimum and the maximum load in a cycle, i.e. $\left.R=P_{\min } / P_{\max }\right)$.

$$
\frac{d a}{d N}=C(\Delta G)^{m}
$$

For a scarf joint containing an embedded disbond, it was found in previous literature [5], that the energy release rate for a given load, $G_{\max }$, at the crack tip can be determined using a reference stress method outlined below:

$$
\begin{aligned}
G_{I, \text { max }} & =\left(\sigma / \sigma_{\text {ref }}\right)^{2} G_{I, r e f} \\
G_{I I, \text { max }} & =\left(\sigma / \sigma_{\text {ref }}\right)^{2} G_{I I, \text { ref }}
\end{aligned}
$$

where $G_{I, \text { ref }}$ and $G_{I I, \text { ref }}$ are the mode I and mode II strain energy release rates when the scarf joint with a flaw of length $a$ is subjected to a reference stress $\sigma_{\text {ref }}$. Under mixed-mode loading, the two individual strain energy release rates can be combined to form a single correlating parameter using the Benzeggagh-Kenane (B-K) fracture criterion [6], which is given by 


$$
G_{B K, \max }=G_{I, \max }+\left(G_{I I, \max }-G_{I, \max }\right)\left(\frac{G_{I I, \max }}{G_{I, \max }+G_{I I, \max }}\right)^{\eta}
$$

Alternatively the mode I and mode II strain energy release rates can be combined using the power law criterion,

$$
G_{\text {power-law,max }}=\sqrt[\alpha]{\left(G_{I, \text { max }}^{\alpha}+G_{I I, \max }^{\alpha}\right)}
$$

For this paper, a value of $\eta=1.75$ was used in the B-K fracture criterion and a value of $\alpha=2$ was used in the power law equation. These values were taken from literature [7] and were noted to provide fairly good predictions of the static strength of composite structures.

The number of fatigue cycles spent in growing a disbond from an initial length of $a_{0}$ to the final critical length $a_{c}$, which is essentially the fatigue life, can be determined by integrating the reciprocal of Equation (1), yielding,

$$
N_{f}=\int_{a_{0}}^{a_{c}}\left(\frac{d a}{d N}\right)^{-1} \mathrm{~d} a
$$

The critical disbond length $a_{c}$ can be determined from the unstable growth condition

$$
\left(\sigma_{\text {max }} / \sigma_{\text {ref }}\right)^{2} G_{B K, \text { ref }}\left(a_{c}\right)=G_{I C}
$$

For a scarf joint containing a disbond of length $a_{0}$, the fatigue limit $\sigma_{F L}$ and static residual strength $\sigma_{U L T}$ can be estimated by

$$
\begin{gathered}
\sigma_{F L}=\sigma_{r e f} \sqrt{\Delta G_{t h} /\left(1-R^{2}\right) G_{r e f}\left(a_{0}\right)} \\
\sigma_{U L T}=\sigma_{r e f} \sqrt{G_{I C} / G_{r e f}\left(a_{0}\right)}
\end{gathered}
$$

where $G_{r e f}$ denotes the reference strain energy release rate according to Equations (3) or (4), depending on the failure criterion. Therefore it is interesting to note that the ratio between the fatigue limit and static strength of a scarf joint is equal to the square root of the ratio between threshold and toughness,

$$
\frac{\sigma_{F L}}{\sigma_{U L T}}=\sqrt{\frac{\Delta G_{t h}}{\left(1-R^{2}\right) G_{I C}}}
$$

which provides a rapid estimate of the fatigue limit from the static test, providing the initial flaw is large enough such as the linear elastic fracture mechanics approach is valid.

\section{Experiments and results}

Adhesively bonded composite scarf joints were first manufactured using VTM264/T700 [8] unidirectional carbon/epoxy composite prepreg with a ply thickness of $0.22 \mathrm{~mm}$, a curing temperature of $120^{\circ} \mathrm{C}$ for 1 hour, and a lay-up of $\left[45^{\circ} / 0^{\circ} / 0^{\circ} / 90^{\circ} /-45^{\circ}\right]_{2 \mathrm{~S}}$. Cured laminates were machined to a $3^{\circ}$ angle using a milling machine and then bonded with VTA260 adhesive at a curing temperature of $120^{\circ} \mathrm{C}$ for 1 hour. Inserts, with a length of $12 \mathrm{~mm}$, were placed at the compositeadhesive interface at the feathered end of the scarf as an initial disbond.

The joints were loaded in static tension under conditions similar to that employed in reference [5] to determine the residual strength of the joint with a disbond length of $12 \mathrm{~mm}$. It was observed that the fracture occurred in the composite adherend near the composite-adhesive interface [5], at a distance from the composite-adhesive interface comparable to a fibre diameter. The joint was observed to have an average static residual strength of $264 \mathrm{MPa}$. The joints were then tested in fatigue with a cyclic loading ratio $(R)$ of 0.1 , at a frequency of $10 \mathrm{~Hz}$, and peak loads at $50 \%, 35 \%$ 
and $25 \%$ of the static residual strength. A travelling microscope was used to capture fracture propagation along the side of the scarf joint. The joints were loaded to failure at $50 \%, 1 \times 10^{5}$ cycles at $35 \%$ and $1 \times 10^{6}$ cycles at $25 \%$.

Fatigue cracks in the scarf joints, at loads of 50\% and 35\% residual strength, were observed to first propagate across the adhesive, from one composite-adhesive interface to the other interface, and then continue travelling down the bondline similar to the static fracture path reported in [5], shown in Figure 1. At the peak load of 50\% residual strength, the joint failed catastrophically after 24,658 cycles. At the peak load of $25 \%$ residual strength, no crack propagation was observed after $1 \times 10^{6}$ cycles, suggesting that the applied peak loads were below the fatigue threshold strength of the joint.

For the composite material system employed in this study, the constants $C$ and $m$, in Equation (1) were determined from literature [9] under Mode I interlaminar DCB fatigue tests $(C=$ 0.08 and $m=4.5)$.

\section{Computational modelling}

Finite element models were developed in Abaqus 6.10 [10] for this analysis. Plane strain four-node orthogonal (CPE4) and three-node triangular (CPE3) elements were used to model the adhesive and the composite adherends, with ply-level mesh refinement. Material properties for the composite plies and the adhesive are listed in Table 1 and Table 2, respectively. The properties of $+/-45^{\circ}$ plies were derived using ply coordinate transformation equations, considering only the terms in the plane of the model [11]. Boundary conditions were applied on both ends of the scarf joint to replicate experimental testing constraints, and consisted of constrained displacements in all degrees of freedom, except for the loading displacement at one end. A non-linear implicit numerical analysis was performed using Abaqus/Standard to account for the effects of secondary bending.

Table 1: Material properties of VTM264/T700 composite

\begin{tabular}{cccccc}
\hline$E_{11}$ & $E_{22}=E_{33}$ & $v_{12}=v_{13}$ & $v_{23}$ & $G_{12}=G_{13}$ & $G_{23}$ \\
\hline $120 \mathrm{GPa}$ & $7.5 \mathrm{GPa}$ & 0.32 & 0.33 & $3.9 \mathrm{GPa}$ & $2.3 \mathrm{GPa}$ \\
\hline
\end{tabular}

Table 2: Material properties of VTA260 adhesive

\begin{tabular}{ccc}
\hline$E$ & $v$ & $G$ \\
\hline $3 \mathrm{GPa}$ & 0.35 & $1.1 \mathrm{GPa}$ \\
\hline
\end{tabular}

Based on the fractographic observations described in the previous section that the fracture occurred in the composite at a small distance comparable to a fibre diameter away from the composite-adhesive interface, the onset and propagation of cracks was assumed to be within the composite, adjacent to the composite-adhesive interface. The effect of the extremely thin layer of resin-fibre material is ignored for simplicity; the crack path was assumed to be along the adherendadhesive interface. With reference to Figure 2, interface 1 represents disbonds and crack paths propagating between the feathered end of a scarfed adherend and the adhesive. Interface 2 represents disbonds and crack paths between the blunt end of the scarfed adherend and the adhesive. The distance $(\Delta a)$ between the nodes along the bondline was refined to approximately $0.264 \mathrm{~mm}$. Using the virtual crack closure technique (VCCT), the strain energy release rates $\left(G_{I}\right.$ and $\left.G_{I I}\right)$ were determined. The results are displayed in Figure 3 for a range of flaw sizes $(a)$, normalised by the length of the scarf $(L)$, under an applied load of 1.0 MPa. From these results, the appropriate strain energy release rates at any given applied load and crack length can be readily computed from Equation (2). 


\section{Comparison between numerical predictions and experimental data}

Numerical predictions were obtained from Interface 2 as shown in Figure 2. Figure 4 shows the effect of mixed-mode criterion on fatigue crack growth loaded at $35 \%$ and $50 \%$ of the residual joint strength. At 35\% residual strength, both criteria appear to correlate fairly well to experimental data. The B-K criterion is observed to perform better than the power-law with $\alpha=2$. At $50 \%$ residual strength, the $\mathrm{B}-\mathrm{K}$ criterion is observed to predict the life of the joint more accurately than the power law. It should be noted that both criteria provided conservative predictions by overpredicting the length of the crack. Overall, this shows that the B-K criterion is capable of accurately predicting the fatigue crack growth behaviour and the life of the composite scarf joints under fatigue loading conditions.

Finally, Figure 5 shows numerical predictions on the life of the joint with an embedded disbond of $12 \mathrm{~mm}$ at various maximum fatigue loads in the form $\mathrm{S}-\mathrm{N}$ curve. A reasonable correlation between experimental data and model predictions can be observed. The S-N curve correctly predicted that the life of the joint at $25 \%$ of the residual strength was higher than $1 \times 10^{6}$ cycles.

\section{Conclusion}

This paper presents a linear elastic fracture mechanics-based methodology for predicting the fatigue life of adhesively bonded composite scarf joints with disbonds. The fracture behaviour and crack path were determined through microscopy. By applying the VCCT along the observed crack path and determining the strain energy release rates at unit loads, the fatigue crack growth rate and life of scarf joints can be accurately predicted.

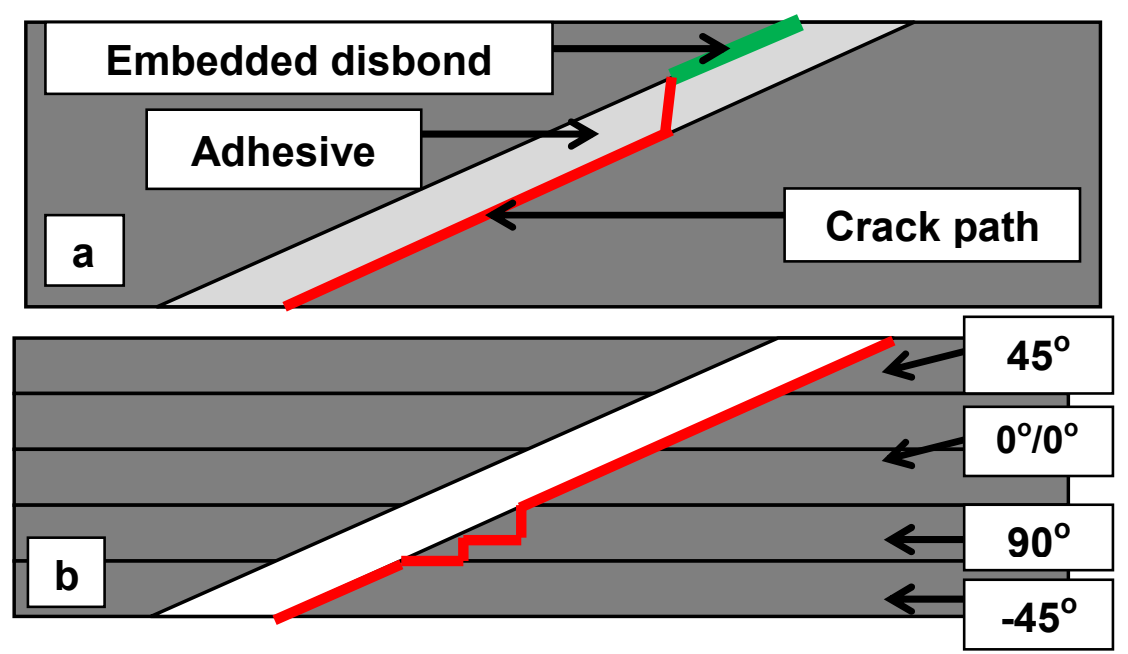

Figure 1: (a) Overall crack propagation in the fatigued scarf joint. (b) Typical crack propagation path near ply terminations. One quarter of the laminate stack shown.

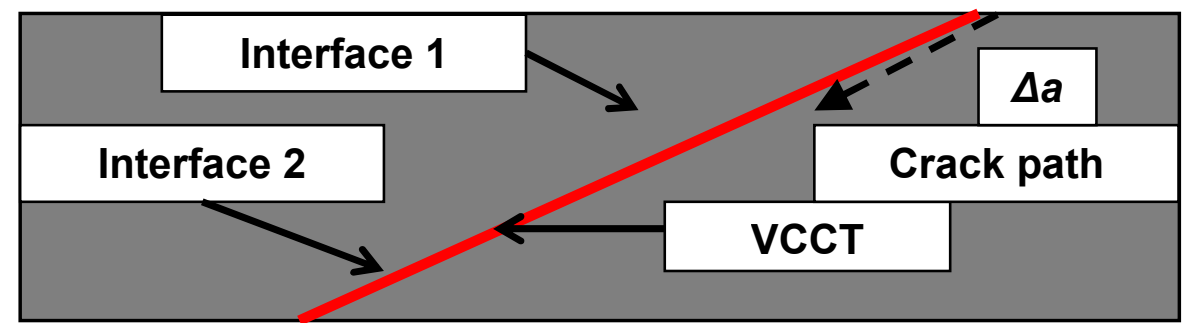

Figure 2: Critical regions of the scarf joint embedded with the VCCT model. Two different numerical models were generated. 


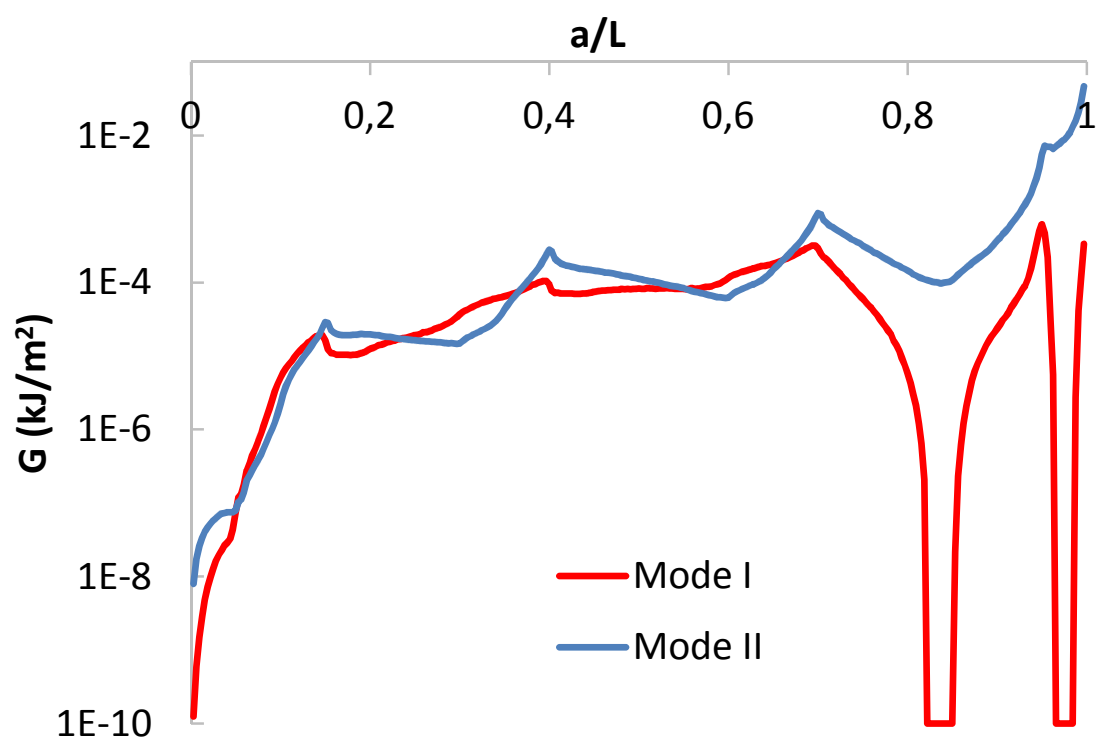

Figure 3: Numerically derived Mode I and II strain energy release rate $\left(G_{I}\right.$ and $\left.G_{I I}\right)$ curves of the scarf joint, under unit load $(1 \mathrm{MPa})$, at a range of flaw sizes $(a)$, normalised by the length of the scarf $(L)$.
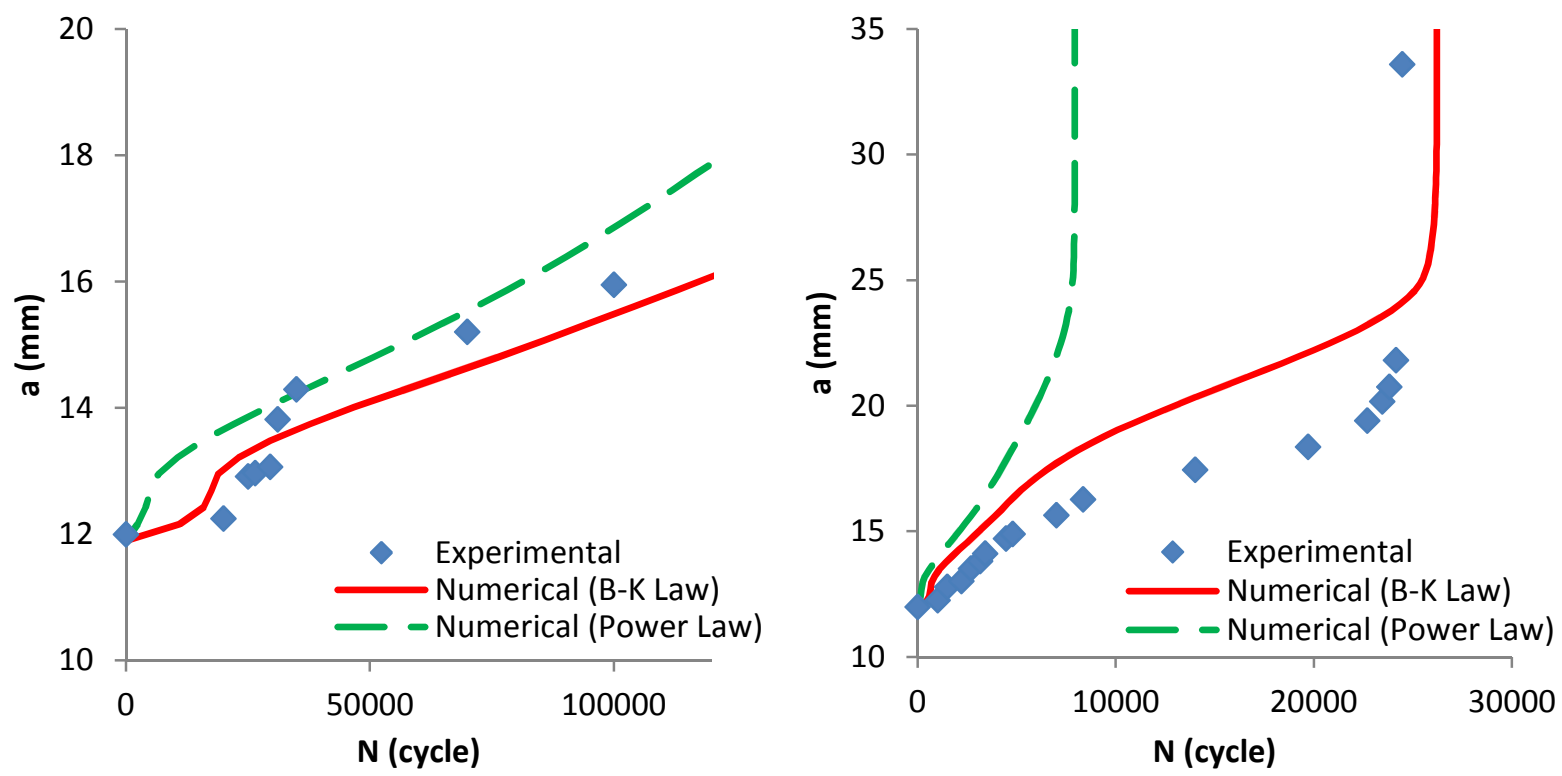

Figure 4: Effect of mixed mode criterion on fatigue crack growth loaded at a) $35 \%$ and b) $50 \%$ of the residual joint strength. (Power Law, $\alpha=2$; B-K, $\eta=1.75$ ) 


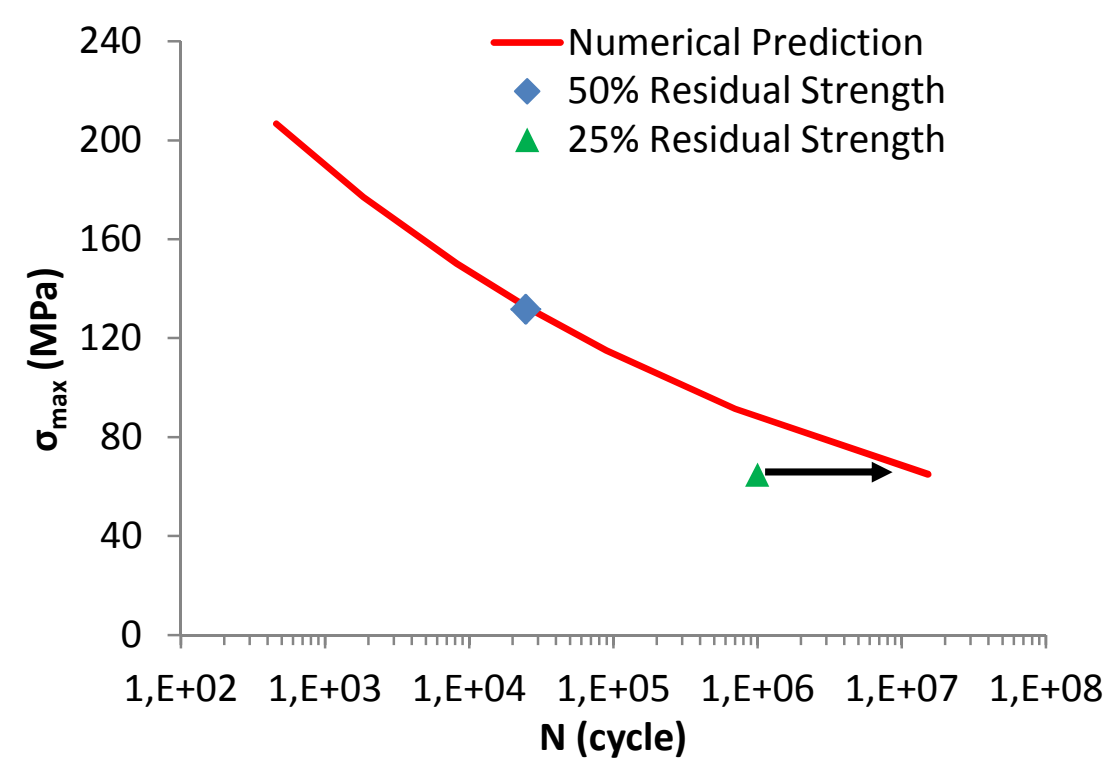

Figure 5: S-N curve of numerical predictions against experimental results.

\section{References}

[1] FAA, Composite Aircraft Structure: Advisory Circular (AC) 20-107B, 2010.

[2] Wang, C.H., Gunnion, A.J., Orifici, A.C., and Rider, A., Residual strength of composite laminates containing scarfed and straight-sided holes. Composites Part A, 2011. 42: p. 19511961.

[3] Goh, J.Y., Georgiadis, S., Orifici, A.C., and Wang, C.H., Effects of bondline flaws on the damage tolerance of composite scarf joints. Composites Part A: Applied Science and Manufacturing, 2013. 55: p. 110-119.

[4] Kim, M.K., Elder, D.J., Wang, C.H., and Feih, S., Interaction of laminate damage and adhesive disbonding in composite scarf joints subjected to combined in-plane loading and impact. Composite Structures, 2012. 94(3): p. 945-953.

[5] Goh, J., Georgiadis, S., Orifici, A., and Wang, C., Effects of bondline flaws on the damage tolerance of composite scarf joints. Composites Part A: Applied Science and Manufacturing, 2013.

[6] Benzeggagh, M.L. and Kenane, M., Measurement of mixed-mode delamination fracture toughness of unidirectional glass/epoxy composites with mixed-mode bending apparatus. Composites Science and Technology, 1996. 56(4): p. 439-449.

[7] Camanho, P.P., Davila, C.G., and de Moura, M.F., Numerical Simulation of Mixed-Mode Progressive Delamination in Composite Materials. Journal of Composite Materials, 2003. 37(16): p. 1415-1438.

[8] ACG, ACG VTM260 Series. Variable temperature moulding prepreg system, 2009, Advanced Composites Group Ltd: Derbyshire, UK.

[9] Pingkarawat, K., Wang, C.H., Varley, R.J., and Mouritz, A.P., Healing of fatigue delamination cracks in carbon-epoxy composite using mendable polymer stitching. Journal of Intelligent Material Systems and Structures, 2013: p. 1045389X13505005.

[10]Abaqus Version 6.10 Documentation2009, Rhode Island, USA: Abaqus Inc.

[11]Wang, C.H. and Gunnion, A.J., On the design methodology of scarf repairs to composite laminates. Composites Science and Technology, 2008. 68(1): p. 35-46. 